\title{
La interpretación del derecho como vocación*
}

\author{
Law's interpretation as a vocation
}

A interpretação do direito como vocação

\section{Carlos de Cores ${ }^{1}$}

${ }^{1}$ Universidad Católica del Uruguay

Orcid: http://orcid.org/ 0000-0003-2715-714X

DOI: https://doi.org/10.22235/rd.v0i19.1776

\section{Comunicación}

RESUMEN: En el presente artículo se aborda el problema de la interpretación del derecho desde el punto de vista del sujeto que interpreta. Sosteniendo que el descubrimiento de los significados ínsitos en los textos normativos no es cuestión de automatismos, se reflexiona sobre el rol que corresponde a la persona que profesionalmente, en función de una vocación elevada, y para cumplir con ella, dedica su vida a la interpretación del derecho.

Palabras ClaVe: interpretación, rol del magistrado, historia del derecho.

ABSTRACT: This article deals with the problem of the law's interpretation from the point of view of the subject who interprets. Affirming that the discovery of the meanings contained in the normative texts is not a matter of automatisms, the study intends to deepen the question of the function of those who devote their lives to the interpretation of the law, aiming to follow a vocation to pursue high goals.

KEY WORDS: interpretation, role of the judges, history of the law.

Recibido: 24/12/18. Aceptado: 02/02/19.

\footnotetext{
* Comunicación preparada por el autor para integrar el volumen especial dedicado a argumentación e interpretación del derecho.

Carlos de Cores Helguera. Abogado (UdelaR), doctor en Derecho (Universidad Pontificia de Comillas) e investigador del Sistema Nacional de Investigadores. Profesor de grado y posgrado de Derecho Civil (Contratos y Daño); actual director del Departamento de Derecho Privado de la Universidad Católica del Uruguay. cdecores@ucu.edu.uy
} 
ReSUmo: Este artigo aborda o problema da interpretação da lei a partir do ponto de vista do sujeito que interpreta. Argumentando que a descoberta dos significados ínsitos nos textos normativos não é uma questão de automatismos, reflete sobre o papel que corresponde à pessoa que profissionalmente, dependendo de uma vocação elevada, e para cumpri-la, dedica sua vida à interpretação da lei.

KEYWORDS: Interpretação, papel do magistrado, história do direito. 
“- Que cherchais-tu?

- Je cherchais qui j'étais."

André Gide, Le retour de l'enfant prodigue ${ }^{2}$

\section{INTRODUCCIÓN}

En Montevideo, los días 24 y 25 de Mayo de 2018, la Facultad de Derecho de la Universidad Católica del Uruguay fue sede de un "workshop" de Filosofía y Teoría del Derecho, dedicado a profundizar el tema de la interpretación y argumentación del Derecho. Dicho encuentro tuvo por objeto proclamado la confrontación de diferentes visiones de la materia, desde el iusnaturalismo al positivismo. El elevado tenor de las ponencias y de las discusiones puso en evidencia la importancia que una adecuada formación y actualización en los temas de Filosofía y Teoría del Derecho posee para todas las disciplinas jurídicas.

Desde la radical modestia y parquedad que conviene a quien confiesa carecer de formación específica en Filosofía, el presente trabajo pretende contribuir al rico debate generado, intentando meramente presentar una perspectiva particular del fenómeno de la interpretación del Derecho: la que parte desde el punto de la profesión del jurista, para el cual se experimenta un llamado, una vocación: la vocación por el Derecho. Si Julián Marías pudo referirse a la Filosofía como el oficio del pensamiento, no es impertinente hablar del Derecho como el oficio de la interpretación. Y si hablamos de oficio, vienen a colación sin esfuerzo, palabras como profesión, misión, servicio o ministerio, o incluso, sacerdocio, todo lo cual lleva como naturalmente a la noción de vocación.

\footnotetext{
2 Tomo esta cita de Paolo Grossi en el proemio de su libro Ritorno al diritto (Bari: Laterza, 2015, p. XIV), porque sintetiza o más bien simboliza el problema que intenta abordar este artículo: el de la vocación, que es siempre una pregunta por el propio ser.
} 
Por cierto, es común escuchar referencias a la vocación del abogado, del notario, del juez o del profesor de Derecho; la perspectiva que se ensaya en este trabajo no refiere en particular a ninguna de esas versiones de la profesión jurídica y tiene en cuenta a todas, postulando que existe una base segura para el desarrollo de la idea de vocación del jurista tout court, como aglutinante genérica de todas esas especies. El objeto observado no consiste, pues, primariamente, en la actividad de interpretación, sino en el sujeto mismo que interpreta, y la intención es señalar la importancia de ciertos aspectos que aluden a ese sujeto en lo que refiere a la interpretación misma.

Por supuesto, para enfocar el problema desde el punto de vista del jurista que interpreta, es menester tener una idea, al menos preliminar o provisoria, de la interpretación, y para ello basta decir, aunque aparezca trivial, que se entiende por interpretación el descubrimiento o la atribución de significados, en particular, de significados de palabras y textos normativos. ${ }^{3}$ Sin embargo, como hablamos de vocación, el centro de la atención será, como indicamos, la persona que experimenta esa vocación.

Emilio Betti se refería a la interpretación como "un fenómeno espiritual del entendimiento, con el cual un espíritu pensante responde el mensaje de otro espíritu, que le habla por medio de formas representativas". ${ }^{4}$ A partir de este texto de Emilio Betti puede intuirse la profundidad humana de la experiencia interpretativa, que involucra a toda la persona, $y$ cuando tiene por finalidad encontrar el sentido de la justicia en las relaciones sociales, constituye la quintaesencia de la vocación por el Derecho. Queda pues colocada en el centro de la atención, la figura del sujeto que hace de la interpretación del Derecho el núcleo de su vida profesional: el jurista.

\section{LA VISIÓN POSITIVISTA DE LA INTERPRETACIÓN}

El propio título con que se ha designado el workshop que nos ocupa: "Interpretación y argumentación. Visiones desde el iusnaturalismo y el iuspositivismo" da la pauta de que ingresamos en un campo con posturas encontradas. Y la propuesta de composición de la controversia que ensayamos postula que la comprensión de este problema, como en realidad de todos, encuentra en la historia un modo insoslayable de abordaje.

Riccardo Guastini, L'interpretazione dei documenti normativi (Milano: Giuffré, 2004), 5.

Emilio Betti, Teoría Generale dell'interpretazione, vol. I Giuffré, Milano, 1955), 55. 
Desde el punto de vista de la experiencia jurídica de los países latinoamericanos, es la Revolución Francesa - entendida incidenter tantum como el complejo proceso que comienza a fines del siglo XVIII con la crisis del antiguo régimen, y se prolonga hasta consolidación del imperio napoleónico - la que representa y sintetiza el pasaje de una visión antigua, a una visión moderna del fenómeno de la interpretación del Derecho. ${ }^{5}$

El problema de la interpretación del Derecho y en particular, la cuestión de la interpretación por parte de quienes tienen la función de aplicar el Derecho, es decir, los jueces, o sea, de la aplicación del Derecho, implica una relación entre la norma y el juez, es decir, entre la ley y el magistrado. Y puede decirse que la concepción de esa relación entre ley y juez que resulta del concreto proceso histórico francés por el cual se deja atrás el ancien régime, deriva en la jerarquización de la ley y la subordinación del juez.

Para entender esta consigna es necesario recordar que en el sistema del antiguo régimen, el modelo era el inverso. El juez medieval, más que aplicador de la ley - que, por otra parte, no existía en el sentido moderno del término - por la vía de un silogismo mecánico en el cual la premisa mayor es la norma legal, la premisa menor es el supuesto de hecho concreto que debe juzgar y la conclusión es la sentencia, era ministro de equidad, y gozaba de un amplio campo de discrecionalidad. ${ }^{6}$ Los magistrados tenían un poder amplio para recurrir a pluralidad de fuentes, que comprendían, junto con textos de Derecho escrito - de difícil determinación -, la consideración de la costumbre, generada radicalmente en los hechos sociales, y la autoridad de los doctores.

Ese modelo político resulta sustituido por un sistema de monismo de fuentes, que tenderá precisamente a restringir el arbitrio de los magistrados que era de tan amplia magnitud - cuya utilización en un contexto de absolutismo político no podía sino generar significativos abusos - imponiéndoles el recurso a una sola fuente: la ley, constituida por la voluntad general promulgada por el legislador, y como paradigma de la ley, el código.

El optimismo racionalista imperante, coherente con la coetánea cosmovisión positivista en el campo de la ciencia, impulsó el proceso de codificación del Derecho, cuya consigna era sentar, en forma sistemática, permanente y definitiva, y susceptible de conocimiento por los ciudadanos, las reglas de Derecho que habrían de ordenar la convivencia humana, elemento necesario para que pudiera imperar el principio de igualdad. La ley debe estar disponible para el conocimiento de todos, se presume el conocimiento de la ley, su ignorancia no sirve de excusa, se predica una función pedagógica de la ley.

\footnotetext{
No tiene características similares la construcción de la separación de poderes en la democracia norteamericana. Alberto Sciume, I Principi generali del diritto nell'ordine giuridico contemporaneo, (Torino: Giappichelli,, 2002).
} 
Todas estas consideraciones están en la base de la idea de codificación. El Derecho positivo codificado, a nivel legislativo, vendrá a constituir la fuente única de Derecho, de la cual el juez no se podrá apartar, y configurará un sistema cerrado, rígido y autosuficiente. Las situaciones no previstas serán reguladas acudiendo a normas análogas o principios existentes dentro del mismo sistema y según los mecanismos rígidamente admitidos.

Como consecuencia, el modelo del juez que es congruente con el espíritu de la codificación es carente de protagonismo. En las conocidas expresiones de Montesquieu, el juez no es sino "la boca que pronuncia las palabras de la ley", llegando el autor a decir que se trata de seres "inanimados"; la función jurisdiccional se convierte así, siempre en palabras de Montesquieu, en "invisible y nula":7 se preconiza la aplicación mecánica de un silogismo, cuya premisa mayor está dada por la Ley, y la premisa menor por los caracteres del supuesto de hecho, resultando en consecuencia la sentencia como conclusión necesaria del razonamiento.

La eliminación del arbitrio judicial, y el trasiego de las competencias de los jueces hacia el legislador, portador de la voluntad general, constituye, pues, indudablemente, uno de los objetivos prioritarios de la codificación del Derecho. El Derecho nuevo se edifica sobre los cimientos de una legislación general, abstracta e igualitaria en la forma, para alcanzar una reductio ad unum de las fuentes del Derecho. La regla de oro de los regímenes de Derecho civil codificado será entonces la simplificación de las fuentes del Derecho y la autointegración. Era claro el designio de personeros como Robespierre, de sustituir en todo lo posible la jurisprudencia, una palabra que según él pertenecía al Antiguo Régimen, y que debe ser borrada del vocabulario del Nuevo, con la legislación, general, abstracta e igualitaria. Según Robespierre, el control del cumplimiento de la ley por parte del Poder Judicial, propio de la Casación, debería quedar a cargo de un Tribunal que perteneciese al Poder Legislativo. ${ }^{8}$

El paradigma del monopolio legislativo y la eliminación del pluralismo de fuentes es patente en el Landrecht prusiano de 1794, que tenía más de 10.000 artículos, y consignaba expresamente que "en los pronunciamientos judiciales futuros no se hará mérito de las opi

\footnotetext{
Carlos Luis Montesquieu, El espíritu de las leyes, capítulo VI, de la Constitución de Inglaterra. Madrid: Biblioteca de Derecho y Ciencias Sociales, Librería General de Victoriano Suárez, 1906, tomo I.

$8 \quad$ Expresaba Robespierre, en la sesión del 18 de noviembre de 1790: "Ce mot de jurisprudence des tribunaux, dans l'acception qu'il avait dans l'ancien régime, ne signifie plus rien dans le nouveau; il doit être éffacé de notre langue. Dans un état qui a une Constitution, une législation, la jurisprudence des tribunaux n'est autre chose que la loi; alors il y a toujours identité de jurisprudence”. Archives Parlementaires de 1787 a 1860, Recueil complet. Societé d'imprimerie et librairie administratives et des chemis de fer, tomo XX, Paul Dupont, Paris, 1885, Convention National, Séance du 18 novembre 1790, p. 516. La discusión comienza el 9 de noviembre de 1790.
} 
niones de los jurisconsultos o de pronunciamientos anteriores". No le es permitido al Juez interpretar el sentido de la ley cuando tuviere dudas (artículo 7), sino que debe dirigirse a una comisión legislativa.

En nuestra comarca, da testimonio de este fenómeno Arturo Caumont, quien ha afirmado que la tripartición de los poderes tuvo por objeto histórico, delineado e institucionalmente canalizado, proporcionar certeza en las relaciones entre los miembros particulares de la comunidad, y claridad en la línea divisoria entre licitud e ilicitud. ${ }^{9}$ En la visión de este profesor, el conjunto de signos que configura un código constituye un sistema completo, que por su carácter científico y abstracto contiene en sí la aptitud de prever todas las situaciones posibles, mediante "la aprehensión anticipada del futuro", que comprende "el universo de posibilidades no finitas" que la propia realidad se encarga de ir presentando”, posibilitando "la posesión del propio tiempo futuro desde el presente en el cual la categoría se construya". ${ }^{10}$ De ese modo, todos los problemas son anticipadamente resolubles desde la abstracción del pensamiento que antecede a la vicisitud práctica. ${ }^{11}$ A partir de estas premisas, el autor postula que la actividad jurisdiccional debe necesariamente partir de la abstracción, de la regla abstracta, para deducir luego su aplicación al caso concreto, y no, por el contrario, "conferir alta relevancia al caso concreto". ${ }^{12}$ Se reconoce que ello podría llevar a una injusticia en el caso, pero "la existencia de soluciones injustas transcurre por andariveles diferentes que el mismo ordenamiento autorregula al plasmar la posibilidad de su propia reformulación”. ${ }^{13}$

En buen romance, desde esta perspectiva, el juez debe limitar su actividad a la aplicación de la regla general y abstracta preordenada, sin inmutarse cuando la misma determine una situación injusta en el caso sometido a su jurisdicción, ya que los criterios axiológicos sobre la justicia como valor son ontológicamente relativos, y por ello no existe la posibilidad de predicar el propio como vinculante respecto de quien pueda tener otro criterio, tan válido y respetable como el contrario. ${ }^{14}$

\footnotetext{
$9 \quad$ Arturo Caumont, "La función jurisdiccional del magistrado es aplicar el Derecho Objetivo. Infungibilidad del poder normativo", en Revista de Derecho de la Universidad Católica del Uruguay, N. ${ }^{\circ}$ VI (2004): 187 ss.

10 Arturo Caumont, Doctrina General del contrato. Proposiciones teóricas de innovación (Montevideo: La Ley Uruguay, 2014), 54; especialmente: “Trascendencia de la manera de pensar en el Derecho. Abstracción y concreción” y "La fundamentación metodológica en el Derecho civil: un imperativo científico insoslayable".

Caumont, "La función jurisdiccional ... 190-191.

Caumont, Doctrina General del contrato..., 73.

Caumont, Doctrina General del contrato..., 77.

Caumont, "La función jurisdiccional .... 187 ss.
} 


\section{CRÍTICA DE LA VISIÓN POSITIVISTA}

La concepción de que el legislador tendría la aptitud para fijar de antemano las reglas idóneas para regular todos los problemas de la vida cotidiana presenta un cariz ideológico, y lo demostró prontamente.

Aun cuando la ideología moderna superó muchas tachas del antiguo régimen, y la doctrina de la separación de poderes constituye una adquisición irrenunciable de toda sociedad civilizada, la versión que de dicha doctrina imperó a partir de la revolución francesa y su desembocadura napoleónica, tuvo como consecuencias la consolidación de un estado con predominancia de un poder legislativo censitario y de reducido carácter representativo. La reducción de la función del intérprete a la de aprehensor de la idea general contenida en la norma legal - por más valiosa que esta función pueda ser considerada sea desde el punto de vista de expresar una elevada factura técnica - coloca al intérprete, al jurista, en una posición que, por una parte, no es la que se verifica en la realidad, y por otra, no le permite cumplir a cabalidad el objetivo que es propio de su profesión u oficio, el sentido de su vocación.

En efecto, la concepción que quiere ver en la ley la única fuente de Derecho, encarnación indiscutible de la justicia legal emanada de la soberanía popular, abstracta y general en su contenido, y garantía de la certeza jurídica y de la previsibilidad de las acciones del ciudadano, presenta el peligro de funcionar como una ideología legitimadora y encubridora de una realidad mucho más compleja, y por cierto mucho menos luminosa para las pretensiones del legislador. ${ }^{15}$

Constituye un lugar común de la literatura de las ciencias sociales que la ideología burguesa e individualista, que pasó a ocupar el lugar dominante en la sociedad moderna, cumplió una función de legitimación de una reducida clase dominante sobre la base de un discurso igualitario pero formalista, con total desatención de la realidad social y económica. Pasó, así, a cumplir, como toda ideología, una mera función de legitimación de una relación de poder. La fuerza incontrastable de los hechos, y la experiencia social que constatara inexorablemente el creciente desajuste entre la realidad y la norma legal superada en su previsión por el vertiginoso cambio social dio lugar a numerosas tensiones y conflictos en los que los sectores populares reivindicaron una visión más realista, generándose por un lado el proceso de socialismo y por otro el Estado social de Derecho. Es de subrayar la importancia histórica

\footnotetext{
15 Leslie Van Rompaey, "Hacia una jurisprudencia principialista”, en Revista de Derecho de la Universidad Católica del Uruguay, Montevideo, 2004, p. 175.
} 
de una generación de juristas franceses de fines del siglo XIX y principios del siglo XX, que mostrando una profunda sensibilidad social, cuestionaron el rol y el ministerio del jurista y el sistema de fuentes del Derecho, que el orden burgués había reducido y unificado a través de la codificación.

Por otra parte, la legislación se hizo fragmentaria, desordenada y casuística, de difícil conocimiento y variabilidad frecuente: la certeza que se pretendía por el legalismo racionalista o positivismo rígido se tornó en inseguridad, frustrándose la pretensión de ordenar la vida social mediante reglas sencillas, duraderas, y respecto de las cuales pueda presumirse su general conocimiento. ${ }^{16}$

Paolo Grossi protagoniza un embate crítico vigoroso contra el positivismo jurídico legalista que - a través de la influencia de la revolución francesa - predomina sin dudas en la cultura jurídica del Derecho civil, ya sea en Europa o en América Latina, comenzando por llamar la atención sobre el rol ideológico del programa político estatalista, formalista, legalista, que él llama "iluminístico-jacobino", ${ }^{17}$ que condujo en definitiva a la reproducción de las tradiciones del absolutismo del ancien régime. El éxito de esta operación política queda demostrado, según Grossi, por la general aceptación de la arbitrariedad del Derecho estatal, de la mano del monopolio de las fuentes por el legislador y de la resignación de que el Derecho reduce su fundamento en una legitimidad formal de kelseniana memoria. ${ }^{18}$

Recién con el desarrollo de la justicia constitucional, y la recuperación del rol efectivo de los principios y reglas constitucionales y derivadas de las convenciones internacionales sobre Derechos humanos fundamentales, se ha recuperado la idea del Derecho como fenómeno más vasto que el mandato formal exclusivo y excluyente del legislador. Este cambio de paradigma lleva a la necesidad de encontrar un fundamento para la legitimidad de la norma que va más allá de la mera consideración formal, y se coloca, por tanto, por una parte, en el plano del contenido, y por otra, de la tensión con la realidad, exigiendo un juicio - construido a partir de una actividad crítica que tiene siempre por objeto la norma legal, pero a la luz de fuentes supralegales y de la consideración de la realidad social - sobre la racionalidad, la justicia y la adaptación de la ley a las necesidades del conjunto de la sociedad real. Interpretación “desde la Constitución”, que constituye una destreza que las sucesivas generaciones de profesionales del Derecho no desarrollaron hasta las postrimerías del siglo XX.

\footnotetext{
16 Van Rompaey, "Hacia una jurisprudencia..., p. 175.

17 Grossi, Paolo, "Le molte vite del giacobinismo giuridico", en Mitologie giuridiche della modernitá, Giuffré, Milano, 2007, p. 125.

${ }_{18}$ Expresión que pertenece a Guido Alpa. V. Guido Alpa, "Disertación al recibir la investidura de Doctor Honoris Causa de la Universidad de Buenos Aires en la Facultad de Derecho”, 27 de marzo de 2008.
} 
Según Grossi, existieron dos coágulos históricos, aparentemente de signo opuesto pero regidos sustancialmente por una misma matriz y una misma ideología jurídica acomunada en la concepción del fenómeno jurídico en clave metahistórica: el movimiento codificador francés, y su natural continuación con la escuela de la exégesis, y la pandectística alemana.

Las constituciones europeas de la posguerra, fundamentalmente de los países que atravesaron por el trauma de los procesos fascistas y nacionalsocialistas, o sea, la constitución italiana de 1948 y la constitución alemana de 1958, han inspirado una nueva consideración del Derecho superadora del monismo legalista.

Grossi compara la concepción de la ley como mandato imperativo del gobernante, propia de la definición de Bodino, con la idea de Derecho, característica de la visión tomista. Según Bodino, "hay mucha diferencia entre el derecho y la ley; el primero registra fielmente la equidad; la ley, en cambio, es sólo el comando de un soberano que ejerce su poder". Para Santo Tomás, en cambio, la ley es considerada como expresión de un orden racional de las conductas orientado hacia el bien común, promulgado por quien tiene la responsabilidad del gobierno de la comunidad. ${ }^{19}$

La visión del derecho desde la Constitución impone el juicio crítico de la racionalidad (razonabilidad) de la ley, convirtiendo el mandato ciego en un precepto ordenante según una racionalidad, la racionalidad constitucional, que gira en torno al respeto de los Derechos fundamentales y dignidad de la persona humana y a la democracia como organización política (art. 72 de la Constitución de la República Oriental del Uruguay). ${ }^{20}$

Grossi identifica los principales postulados integrados sólidamente entre sí en la cosmovisión jurídica de la modernidad: la estatalidad del Derecho privado, esto es, el reconocimiento novedoso y absorbente del Estado como fuente casi exclusiva del Derecho, incluso del privado; el dogma consecuente de la omnipotencia jurídica del legislador; y la identificación de la labor interpretativa como la simple investigación de lo que fue, inicialmente, la intención del legislador, constriñendo al intérprete en una suerte de vínculo obligado flanqueado por murallas impenetrables que impiden todo contacto de su itinerario con el mundo externo.

La creciente complejidad de la sociedad posmoderna ha determinado la obsolescencia de este absolutismo jurídico, que aparece como un vestido demasiado apretado para la necesaria movilidad, libertad y autonomía del orden jurídico.

\footnotetext{
19 «Lex est quaedam rationis ordinatio ad bonum commune, ab eo qui curat communitatis habet promulgate». Santo Tomás de Aquino, Summa Theologiae, II-II, q.90, a.4, C.

20 Paolo Grossi, “Modernità política e ordine giuridico", en Quaderni Fiorentini 27 (1998): 13 y ss.
} 
La crítica histórica conduce pues ineludiblemente a distinguir conceptualmente el Derecho, de la ley. No hay Derecho sin ley, pero el Derecho no se reduce a la ley. La ley en sí, es rígida; el Derecho se estructura en el molde de la ley, pero es flexible. ${ }^{21}$ Como se señala en la explicitación de los Fundamentos del Proyecto de Código Civil y Comercial de la Nación Argentina, "una identificación entre ambos no es admisible en el estadio actual de la evolución jurídico-filosófica”, por lo cual se recoge una concepción que "tiene antecedentes en otros Códigos, como, por ejemplo, el italiano, que se refiere a las fuentes (artículo 1), mencionando a la ley, los reglamentos y los usos, a los que luego define en sus efectos y relaciones jerárquicas (art 2, 3, 4). En el capítulo segundo (art 10) regula la aplicación de la ley (art 11), su eficacia en el tiempo, y la interpretación (art 12). Por esta razón, sugerimos incluir un título "Del derecho" y luego otro referido a la ley como fuente principal". ${ }^{22}$

Y ese complemento que convierte la ley en el Derecho, resulta de la perspectiva del jurista que a partir de un esquema pluralista de fuentes, no contentándose con una mera validez procedimental y formal de la norma legal, es capaz de exigir a la ley un fundamento racional y conforme, por un lado, con los valores y principios constitucionales, y por otro, con los fines prácticos a los que se orienta la producción del derecho.

\section{REVALORIZACIÓN DEL PAPEL DEL INTÉRPRETE Y EN PARTICULAR DEL JUEZ}

En esa perspectiva, parece claro que si bien el rol del juez no es ajeno al procedimiento de conocimiento de la realidad, y en particular, de la norma legal, propio de la ciencia, difiere bastante del de un científico como lo sería un filólogo o un lingüista. La función del juez no se parece tanto a la de un investigador científico que busca enunciar una verdad con validez universal, sino la de un miembro de la comunidad política dotado de autoridad que busca resolver un conflicto concreto entre intereses en forma pacífica, esto es, con un fundamento persuasivo, que proporcione al fallo una legitimidad social. Ello va más de la mano con disciplinas como la retórica y la argumentación, que buscan convencer al auditorio de la plausibilidad de la solución decretada. En efecto, el juez tiene por competencia concreta resolver un conflicto práctico entre particulares, aplicando el Derecho. Y el Derecho es algo diferente

\footnotetext{
${ }^{21}$ Coinciden en esto dos obras clásicas de un jurista francés (Jean Carbonnier, Flexible droit) y uno italiano (Gustavo Zagrebelsky, Il diritto mite).

22 Fundamentos del Código Civil y Comercial de la Nación Argentina.
} 
de la ley, aunque la cultura jurídica de la modernidad ha identificado ambos términos, y ha calificado al juez como un aplicador bastante mecánico del Derecho. Al decir de Piero Calamandrei, la labor del jurista nunca se limita a un proceso meramente cognoscitivo y teórico, sino constituye también un acto práctico con el cual contribuye a la creación de la ley del caso concreto y, de tal forma, contribuye a la modificación y al progreso del Derecho. ${ }^{23}$

Por cierto, aún la aplicación literal de la ley requiere una actividad intelectual que necesita a su vez una formación y una capacitación en la habilidad para el pensamiento abstracto. Con el ensayo de Bobbio 'Scienza giuridica e analisi del linguaggio', publicado en 1950, quedaba clara la necesidad de rigor metodológico en la actividad del jurista práctico. Tiene también razón Irti cuando afirma que el trabajo del jurista sobre el lenguaje es un continuo ascender de los signos lingüísticos a los significados, ya sean reales o lógicos, y que el mundo del Derecho es el mundo del lenguaje, de la palabra precisa, y definida, y no de la informe "realidad" o del turbio irracionalismo. ${ }^{24}$

Sin embargo, el sentido común indica que la ley no puede preverlo todo; o al menos que una previsión que comprenda lógicamente todas las posibilidades deberá ser tan vaga que tendrá una utilidad escasa para la resolución de problemas concretos complejos que son generalmente materia de la disciplina jurídica. Es cierto que puede afirmarse abstractamente que todas las obligaciones son de dar, de hacer o de no hacer, y que todas las obligaciones concretas deberán entrar en una de esas categorías (que por otra parte, no son lógicamente exhaustivas). Pero existirán muchos problemas prácticos que no podrán resolverse en base a la inclusión del supuesto en una de las categorías abstractas diseñadas por la ley. La afirmación de que la totalidad de las vicisitudes de la realidad están contenidas en la abstracción de las categorías legales predefinidas en la mens legis no pasa de ser, en la mayoría de los casos, una hipótesis, que seguramente sea falsa, ya que por más racional que sea la obra del legislador o del codificador, no deja de ser una obra humana y por lo tanto, imperfecta. ${ }^{25}$

Es, por lo tanto, necesario, que un sujeto imparcial, distinto del legislador, efectúe la consideración de las circunstancias del caso concreto y de la adaptación o no de la norma general y abstracta a dichas circunstancias, con el objetivo de llegar a una solución justa, porque la justicia es el fin del Derecho.

\footnotetext{
23 Piero Calamandrei, "Fede nel diritto", Conferencia inédita presentada en Firenze el 21 de enero de 1940, citada por Guido Alpa en la disertación al recibir la investidura de Doctor Honoris Causa de la Universidad de Buenos Aires en la Facultad de Derecho, 27 de marzo de 2008.

24 Natalino Irti, "Moralita de l'analisi linguistico", en www.juscivile.it.

25 En el mismo sentido, Jorge Gamarra, "Las circunstancias del caso concreto en la interpretación y aplicación de la ley “, en Revista de Doctrina y Jurisprudencia de Derecho Civil, FCU, tomo II (2014): 94.
} 
Desde el punto de vista institucional, si ha de admitirse el axioma de la separación de poderes, debe reconocerse que el juez no se encuentra sobre el legislador, de modo de poder crear la norma; pero tampoco se encuentra por debajo del legislador, sino en su mismo nivel; y ello provoca una tensión que no puede resolverse en forma simple y lineal, con el recurso de afirmar que el juez carece del poder de crear normas y reduce su competencia a descubrir significados abstractos contenidos ex ante en la norma legal. Para ello no debe convertir en criterio de discernimiento su propia arbitrariedad, sino la regla obligatoria abstracta y general, que ha establecido no él, sino el legislador. Pero el descubrimiento del sentido jurídico encerrado en las fórmulas legislativas y su aplicación al caso concreto requiere una operación más compleja que la mera subsunción silogística. Por un lado, la pluralidad de sentidos contenidos usualmente en las palabras del lenguaje natural; y por otro, la pluralidad de normas de cualquier ordenamiento con potencialidad de ser aplicadas al caso concreto, que exorbitan, la mayor parte de las veces, la exclusión de unas por otras según los conocidos principios de jerarquía, derogación y competencia, requieren por parte del intérprete, de capacidades operativas que estaban desarrolladas en los juristas medievales y que han quedado de alguna manera atrofiadas en el paradigma del intérprete moderno.

La aplicación lineal de la ley se parece más a la función administrativa que a la jurisdiccional; aunque tampoco la función administrativa excluye el juicio crítico del administrador y su consideración de las normas constitucionales y las circunstancias de tiempo y lugar.

Sin dejar de reconocer los obvios progresos que la modernidad jurídica trajo consigo al imponer la idea de que todos los ciudadanos estamos igualmente sometidos a la ley, es conveniente fijar la atención sobre las consecuencias del imperio de la codificación sobre los sujetos que interpretan el Derecho.

Como hemos visto, fue objetivo político expreso de la revolución francesa eliminar la necesidad de la mediación del estamento de los juristas en la interpretación y aplicación del Derecho y, en particular, el de sustraer a los jueces todo poder discrecional al respecto, pretendiendo que los matices aplicativos estuvieran ya contenidos de forma general y abstracta en los textos legislativos y vedando todo protagonismo al intérprete. Por cierto, tal actitud tenía su justificación, ya que los juristas del antiguo régimen se habían excedido en muchas ocasiones pasando de la aplicación a la creación del Derecho, actuando como un poder conservador que impedía la innovación que pretendía introducir el poder político. ${ }^{26}$ Sin embargo, la concepción del intérprete como un mero descubridor de significados ya

26 Carlo Granelli, "La giurisprudenza è fonte di diritto?": Introduzione ad un incontro di studi, 30 settembre 2016, in occasione della presentazione dei due volumi degli "Scritti giuridici di Andrea Belvedere", Padova, 2016, en www.iuscivile.it. 
contenidos en la ley, considerada como receptáculo preconstituido de la totalidad de soluciones de los futuros conflictos entre los particulares, no parece responder a la realidad de la experiencia jurídica.

En suma: en el Estado legislativo de Derecho, la vinculación del juez a la ley se postula en términos de mera subordinación: frente al legislador, que posee una legitimidad política o 'de origen', los jueces solo tienen una legitimidad 'técnica' o 'de oficio'; es decir que su actuación será aceptable en la medida que pueda verse como la exacta aplicación de la ley. ${ }^{27}$ Sin embargo, la ilusión de leyes "auto-aplicativas", de normas tan claras, completas y no contradictorias que permitan una aplicación puramente automática y mecánica, resulta desvanecida frente a la evidencia de los hechos: no hay ninguna disposición legislativa que se sustraiga a la exigencia de interpretación y aclaración; existen lagunas en el ordenamiento, ya sea motivadas por descuidos del legislador, o por el advenimiento de hechos no previsibles en la época de sanción de la ley; es necesario adaptar las reglas legales, inmutables en su formulación literal, a la evolución de las exigencias prácticas de la sensibilidad social. ${ }^{28}$

Si bien algunas reacciones contra el estatalismo legalista, como la conocida escuela del Derecho libre de principios del siglo XX, son generalmente reputadas excesivas, han permitido tomar conciencia de que el ordenamiento jurídico está compuesto no sólo de leyes, a quienes debe reconocerse, sin duda, un lugar preeminente, sino de otras fuentes, como las orientaciones jurisprudenciales de indudable vigencia, opiniones de la doctrina, hábitos de comportamiento de los ciudadanos, etc. ${ }^{29}$

La puesta en valor de las normas constitucionales y de las declaraciones supranacionales de Derechos humanos fundamentales, que enuncian principios generales de aplicación inmediata que a veces matizan o incluso cuestionan disposiciones de la ley, impone volver la mirada hacia el rol de aquel grupo de personas que en cada sociedad ha hecho de la interpretación y aplicación del Derecho, su profesión: los juristas.

Esta atención sobre el jurista resulta necesaria no como consecuencia de una reivindicación corporativista, sino a partir de la progresiva toma de conciencia de que el Derecho no nació con la Revolución francesa; que una visión madura requiere insoslayablemente tener en cuenta que el edificio del Derecho es resultado de una larga evolución histórica, y que en esa evolución, un largo trecho correspondió a la etapa en que se asignaba a la profesión del jurista un rol de mayor relieve en la interpretación y aplicación del Derecho. El jurista antiguo había generado la destreza en la tarea de conocer los preceptos generales derivados

\footnotetext{
Leslie Van Rompaey, “Hacia una jurisprudencia...”, p. 173.

Carlo Granelli, "La giurisprudenza...”, op. cit..

Fiorenzo Festi, "L'arbitrato di equità", en Contratto e impresa (Padova: Cedam, 2006), p. 141.
} 
de varias fuentes (la scientia) y amalgamarlos en la consideración de su propia conciencia (la conscientia) y de las circunstancias del caso concreto, para descubrir el Derecho aplicable y llegar a la solución justa.

La más acotada función del intérprete en la etapa de la modernidad jurídica ha hecho perder a los juristas la conciencia de que su función no se agota en el análisis literal de los textos, implicando - al decir de Paolo Grossi - una pesada hipoteca cultural ${ }^{30}$ que sólo las acuciosas necesidades del tiempo presente, de relevante complejidad, han ido levantando.

Una reflexión - aún breve y restringida - sobre el significado de la interpretación en el Derecho no hará sino confirmar este punto de vista.

\section{ACERCAMIENTO CRÍTICO}

\section{A LA TAREA DE INTERPRETACIÓN}

Según Guastini, interpretar textos es atribuir un significado (sentido) a un fragmento de lenguaje. La interpretación jurídica pertenece al género de las interpretaciones textuales. Se puede interpretar: fuentes del Derecho, actos de autonomía privada, actos jurisdiccionales, actos administrativos, etc. ${ }^{31}$ La actividad interpretativa puede ser puramente cognoscitiva u orientarse a la aplicación (solución de controversias). Nos referiremos primordialmente a esta última.

El texto interpretado es el objeto de la actividad de interpretación y está redactado en el lenguaje-objeto. El discurso del intérprete constituye el meta-lenguaje que refiere a un lenguaje-objeto. ${ }^{32}$ Por su parte, el lenguaje-objeto expresa la disposición, que es el enunciado normativo contenido en la fuente. Es el objeto de la interpretación.

Recién luego de la actividad interpretativa, que consiste en desentrańar el significado de la disposición, se obtiene la norma, que según Guastini, es el contenido significativo de la disposición, de lo que se deduce que una misma disposición contenida en una fuente, puede dar lugar a varias normas.

La doctrina de que todos los significados se encuentran presente en los textos legales y el intérprete no tiene que hacer otra cosa que descubrirlos, se encuentra actualmente desacreditada. Por un lado, se afirma la necesidad de la tarea interpretativa, y la consecuente

\footnotetext{
Paolo Grossi, Ritorno al diritto (Bari: Laterza, 2015), p. VII.

Riccardo Guastini, Linterpretazione dei documenti normativi (Milano,Giuffré, 2004), p. 4,

Guastini, L'interpretazione dei...., p. 137
} 
inviabilidad del "in claris non fit interpretatio". Por otro, la progresiva toma de conciencia de que el jurista no acude desnudo a la tarea interpretativa, sino que enfrenta los textos con todo el bagaje de su estructura personal. Se concibe así la tarea interpretativa como un andarivel de ida y vuelta, que comprende una sucesión de etapas de precomprensión, análisis y nuevo acercamiento al texto-objeto. ${ }^{33}$ Hay una primera expresión, luego la crítica o reflexión y luego una fase superior, que completan un continuado "círculo hermenéutico", en la expresión de Heidegger. ${ }^{34}$ Gamarra refiere al "círculo interpretativo" entre la norma y el hecho. ${ }^{35} \mathrm{El}$ círculo hermenéutico es un sintagma que ha permitido poner de relieve que el intérprete no se limita a conocer lo que dice la norma general, sino que concurre a esta actividad dotado de un bagaje de preconceptos que no determinan pero sí condicionan el proceso de determinación de los significados de la disposición interpretada.

A partir de estas ideas, Guastini describe tres clases de teorías sobre la interpretación: cognitiva, escéptica y mixta. Según la teoría cognitiva, la interpretación es un acto de conocimiento o descubrimiento de un significado objetivo. Hoy día está como tal desacreditada. Según la teoría escéptica, la interpretación no es un acto de conocimiento, sino de sola voluntad, de decisión, de elección. En su variante extrema, la teoría legitima al intérprete para que elija libremente el significado; en su variante moderada, sostiene que la interpretación arroja siempre varios significados en competencia, y el intérprete debe escoger uno. Finalmente, se concibe una teoría ecléctica, para la cual hay un núcleo donde hay actividad fundamentalmente cognoscitiva, y una franja de penumbra, que refiere fundamentalmente a los casos complejos (hard cases en la terminología que surge de la polémica Hart-Dworkin) donde hay decisión. ${ }^{36}$

Sea como fuere, la tarea interpretativa se concibe como una cadena de razonamiento, $\mathrm{y}$ es generalmente requerido que su resultado se encuentre fundamentado en una motivación, lo cual es muy claro y jurídicamente obligatorio en el caso de la decisión judicial. Esta justificación puede ser interna o externa. La justificación interna o de primer orden es la coherencia lógica deductiva desde la premisa a la conclusión. Se incluye la exigencia de que entre las premisas haya premisas normativas, no solamente premisas cognoscitivas. La justificación externa es la elección de la premisa. ${ }^{37}$ Es en este punto donde centraremos el desarrollo del análisis.

\footnotetext{
Guastini, L'interpretazione dei..., p. 22.

Hans-Georg Gadamer, Verdad y método (Salamanca: Ediciones Sígueme, 2003), p. 331 y ss.

Jorge Gamarra, "Las circunstancias del caso ..., p. 93.

Guastini, L'interpretazione..., p. 32 y ss.

Guastini, L'interpretazione..., p. 123.
} 


\section{INTERPRETACIÓN Y ELECCIÓN DE LAS PREMISAS}

Es claro que, en la elaboración de un discurso interpretativo-aplicativo, la formación y el encadenamiento de los juicios para llegar a la conclusión partiendo de la premisa mayor, no puede presentar falencias lógicas, y en ese campo el margen de discrecionalidad es en realidad inexistente, puesto que la lógica constituye una ciencia formal y rigurosa. En cambio, es admitido que en la elección de la premisa mayor de la cual parte el raciocinio que culminará en la conclusión aplicativa, los sistemas jurídicos brindan un amplio margen de discrecionalidad a los jueces, lo cual permite a la teoría apreciar dos cosas: a) que en la selección de las premisas ya se juega buena parte del fallo, sea o no consciente de ello el juez; b) que el control público sobre esa selección es muy laxa: sólo se exige que sean premisas provenientes del propio sistema, que estén dotadas de cierta jerarquía sobre otras premisas normativas del razonamiento; que (alguna de ellas al menos) tengan carácter normativo, porque si no sería lógicamente imposible extraer conclusiones normativas (fallo); que sean plausibles, esto es compartibles por la comunidad crítica; que guarden una conexión semántica razonable con el caso planteado. ${ }^{38}$

Es entonces la actividad de selección de las premisas lo que debe ponerse sobre el tapete. Es notable cómo el genio de Cicerón contemplaba esta perspectiva con total exactitud. En sus Tópicos, fundándose en la autoridad de Aristóteles, aludía a la tarea de construcción retórica de un argumento persuasivo (ratio disserendi), ${ }^{39}$ distinguiendo claramente el ars inveniendi y el ars iudicandi, ${ }^{40}$ y señalando que se puede ser muy competente en la ciencia de la lógica, pero no haber trabajado la habilidad de encontrar (ars inveniendi) los argumentos adecuados (tópicos). ${ }^{41}$

La retorica es el arte de hablar y de escribir de modo apropiado y eficaz, capaz de convencer al auditorio de las tesis propugnadas. Desde este punto de vista, toda sentencia se presenta como un "producto retórico", por el hecho de que su redacción responde a técnicas

\footnotetext{
38 Oscar Sarlo, "Derechos fundamentales y proceso concursal", en Anuario de Derecho Civil Uruguayo, tomo XXXIX, FCU, Montevideo, 2009, p. 871.

39 Del latín dissero, tejer o entrelazar, lo que describe gráficamente la actividad de ligar unos argumentos con otros en un tejido coherente y persuasivo.

${ }^{40}$ Alejandro Guzmán Brito, "Dialéctica y retórica en los Topica de Cicerón”, en Revista de Estudios históricojurídicos, XXXII (2010), Valparaíso, Chile, 161-195.

${ }^{41}$ En Marco Tulio Cicerón, Top. II, 6: "Cum omnis ratio diligens disserendi duas habeat partis, unam inveniendi alteram iudicandi, utriusque princeps, ut mihi quidem videtur, Aristoteles fuit. Stoici autem in altera elaboraverunt; iudicandi enim vias diligenter persecuti sunt ea scientia quam dialektikén appellant, inveniendi artem quae topiké dicitur, quae et ad usum potior erat et ordine naturae certe prior, totam reliquerunt".
} 
de redacción, estudiadas a propósito para potenciar el efecto persuasivo de la comunicación. En esa construcción, la "Inventio" coincide con el momento de selección de los argumentos útiles para sostener la propia tesis; a la "Inventio" sigue la "Dispositio". Si de la capacidad inventiva surge una pluralidad de argumentos, el paso sucesivo será forzosamente la disposición de los argumentos en una secuencia que resulte más eficaz a los efectos de la persuasión. El tercer paso, la Elocutio, consiste en trasponer las ideas en forma lingüística, que sea la más clara, precisa y concisa posible. ${ }^{42}$

$\mathrm{El}$ arte de encontrar argumentos plausibles no puede dominarse sin adquirir una cultura humanística y general. La recuperación de la dimensión sapiencial del Derecho parte de la posesión del sensus communis, sentido comunitario, que se nutre de la experiencia acumulada y de la consideración de las vidas y obras ejemplares que conforman la tradición espiritual de la humanidad. Por otra parte, la elocuencia proveerá el fundamento para justificar frente a la comunidad la elección de la premisa. Según Gadamer, el recurso a la tradición humanista opera como alternativa del método científico en las ciencias del espíritu, recuperando el ideal humanístico de la elocuencia, el arte de decir algo bien y decir el bien. ${ }^{43}$

Pero además, el intérprete busca el supuesto abstracto normativo con la finalidad de resolver su aplicación al caso concreto, y para ello es imprescindible que desarrolle la virtud de la prudencia, que se sustenta en la capacidad de percibir las características relevantes de una situación dada, y capta la medida en que es posible encontrar la mejor solución al conflicto suscitado. La adquisición de esta habilidad supone un período prolongado de formación que además de proveer al jurista de las capacidades de pensamiento abstracto, le permite madurar desde el punto de vista emocional y afectivo y adquirir experiencia y astucia que son esenciales para la adquisición del sentido común.

En la primera redacción del proyecto de código civil sardo, fuente de nuestro código civil, el título preliminar preveía, como el nuestro, la posibilidad de que el juez se encontrara con un "caso difícil”, no susceptible de ser resuelto por las palabras y ni siquiera por el espíritu de la ley. Entonces encomendaba al juez el recurso a los principios generales, y a las circunstancias del caso, "maduramente ponderadas". ${ }^{44}$ La formación y el ejercicio de la madurez en la ponderación de las circunstancias constituye, ni más ni menos, la quintaesencia de la prudencia judicial, y no es ajena al propio ser del intérprete que, al interpretar, responde a su propia vocación.

\footnotetext{
42 Luigi Pellecchi, "La costruzione retorica della sentenza”, en www.juscivile.it (Relazione tenuta dall'Autore presso la Scuola Superiore della Magistratura, nell'ambito del Corso Il linguaggio della giurisdizione (Firenze, Accademia della Crusca, 20 giugno 2016).

43 Gadamer, Verdad y método, p. 47.

44 Alberto Sciumè, "I principi generali del diritto nell'ordine giuridico contemporaneo (1837-1942), en Il diritto nella storia”, Collana diretta da Umberto Santarelli (Torino: Giappichelli 2002) 42, nota 41.
} 


\section{LA INDAGACIÓN PERSONAL DE LOS HECHOS DEL CASO. INMEDIACIÓN QUE NO PUEDE TENER EL LEGISLADOR}

Cuando se trata de la aplicación del Derecho, el tema de la elección de la premisa no está separado de la consideración de los hechos particulares del caso.

Recientemente entre nosotros, Gamarra ha estudiado monográficamente la cuestión de la trascendencia de las circunstancias concretas del caso en la aplicación del Derecho, lo que reitera la relación entre norma general y caso particular, ${ }^{45}$ en interacción recíproca.

En modo alguno puede aceptarse la nimiedad de las circunstancias del caso en relación con la previsión abstracta contenida en el supuesto normativo. El Derecho nació de los hechos. En la formulación literal del Digesto, en el libro Cincuenta (de diversis regulis iuris antiqui), se establece la siguiente formulación: "Regla es lo que narra brevemente la cosa que es. El Derecho no se toma de la regla, sino que la regla se hace con arreglo al Derecho que hay”. ${ }^{46}$ Este pasaje se presenta como verdaderamente enigmático para el jurista contemporáneo, imbuido en la cultura legalista de la identificación del Derecho con la norma legal general. En la concepción prevalente, el Derecho se toma de la regla; lo que dice el pasaje citado es lo contrario: la regla se toma del Derecho; el Derecho lo han construido los jurisconsultos en relación a casos concretos, resolviendo con equidad situaciones de hecho; es a partir de ellos que pueden hacerse formulaciones generales (regulae) pero con mesura, porque el cambio relevante de las circunstancias de hecho (rerum) determina que ya sea inaplicable (simul quum in aliquo vitiata est, perdit officium suum).

Esa radical existencia del Derecho en los hechos de la vida ha llevado a Vassalli a postular la extraestatalidad natural del Derecho civil, ya que el Derecho privado, tal cual lo heredamos del Derecho romano, es independiente de la organización estatal. Elaborado día tras día en las relaciones y tráficos de la vida ordinaria según las enseñanzas del sentido común y de aquél mínimo ético del cual el hombre común es natural portador, el Derecho privado es fruto de una sedimentación lentísima y de una lentísima pero orgánica absorción por parte de la sociedad: con dos protagonistas a nivel técnico jurídico: un privado, el jurisconsulto, y un magistrado, el pretor, que no impone su regla sino que se limita a decir el Derecho, ius

\footnotetext{
Jorge Gamarra, "Las circunstancias del caso..., p. 91 y ss.

1. Paulus libro XVI,. ad Plautium. "Regula est, quæ rem, quæ est, breviter enarrat. Non ex regula ius sumatur, sed ex iure, quod est, regula fiat. Per regulam igitur brevis rerum narratio traditur, et ut sit Sabinus, quasi causæ coniectio est, quæ, simul quum in aliquo vitiata est, perdit officium suum.”
} 
dicere, a declarar lo que es el Derecho en la singular relación en contestación; jurisconsulto y pretor, uno y otro voces de lo bueno y lo equitativo. ${ }^{47}$

\section{EL INTÉRPRETE, SACERDOTE}

La función de declarar lo que es Derecho en las relaciones singulares en conflicto, ${ }^{48}$ va de la mano de la idea de sacerdocio, como se sentían y lo proclamaban los jurisconsultos romanos:

Al ocuparnos del Derecho primero es necesario saber de dónde procede el término "Derecho". [Su nombre] viene de "justicia”; pues, como elegantemente define Celso, el Derecho es el arte de lo bueno y lo equitativo.

$\$ 1$. En mérito de esto alguno nos llama «sacerdotes”, pues servimos a la justicia y nos dedicamos al conocimiento de lo bueno y lo justo, separando lo justo de lo inicuo, discerniendo lo lícito de lo ilícito, deseando conseguir hombres buenos no sólo por el miedo de las penas sino también por el incentivo de los premios, siguiendo, si no me equivoco, la verdadera filosofía y no una falsa. ${ }^{49}$

Como expresa Sarlo, sólo quienes han sido "ordenados" como juristas, pueden aspirar a ser reconocidos como cultivadores de esta disciplina, fundamentalmente porque la validez de sus enunciados se corrobora institucionalmente por la autoridad de quien los emite, y esto depende del reconocimiento que se ganen entre sus colegas, en la docencia universitaria, y en particular, entre los jueces. ${ }^{50}$

No es impertinente, por tanto, insistir en este aspecto de la tarea interpretativa, llevada a cabo, en definitiva, por un jurista que antes que nada, quiere y debe saber, igual que el hijo pródigo, quién es y cuál es su vocación y misión en este mundo. Y aun cuando sus contornos se presenten vagos e imprecisos, la idea de justicia no puede ser ajena a esa vocación, porque no es ajena a la idea de Derecho. Zagrebelsky ha escrito que es difícil definir la justicia, pero existe una experiencia de justicia y mejor aún, una experiencia de injusticia. Una

\footnotetext{
47 Paolo Grossi, "Il disagio di un legislatore. (Filippo Vassalli e le aporie del assolutismo giuridico)", en Quaderni Fiorentini XXVI, 2007, p. 415 y ss.

48 Filippo Vassalli, "Estrastatualitá del diritto civile", en Studi in onore di Antonio Cicu (Milano: Giuffré, 1951), Volumen segundo, p. 479 y ss..

49 Digesto $1,1,1$.

50 Oscar Sarlo, "El marco teórico en la investigación dogmática”, en Observar la ley: ensayos sobre metodología de la investigación jurídica, coord. Por Christian Courtis; Manuel Atienza Rodríguez (pr.), (Madrid: Trotta, 2006), ISBN 84-8164-862-0, 175-208.
} 
formación personal (selbst bindung) que no desatienda esa dimensión parece imprescindible en relación con la misión y vocación de los juristas. ${ }^{51} \mathrm{Y}$ eso tiene que ver con la superación de una enseñanza del Derecho puramente formalista que es la que ha imperado en la cultura contemporánea.

\section{QUE LOS JURISTAS PUEDAN SER LO QUE SON}

Son gráficas las expresiones de Filippo Vassalli: "Richiamare il diritto ai giuristi", ${ }^{52}$ y de Paolo Grossi: "Ritorno al diritto". ${ }^{53}$ Ambas llaman la atención sobre el rumbo del pensamiento que impone una mirada reflexiva y dotada de perspectiva histórica. Ambas urgen a volver sobre sí, a recordar los momentos iniciales de la vocación por el Derecho que en mayor o menor medida, siempre contiene un anhelo de mayor justicia en las relaciones humanas, y a reflexionar sobre ese origen de la vida de cada jurista para reformular y actualizar un compromiso con valores nobles y elevados, que en una sociedad pluralista implican la coexistencia de concepciones totalizantes llamadas a convivir en un diálogo tolerante.

No la ausencia convicciones, sino la admisión de la pluralidad de concepciones y el esfuerzo perseverante por encontrar los ámbitos de coincidencia que enriquecen la cultura de las sociedades. Desde la mirada de una Universidad Católica como la que albergó el "workshop" que motiva esta contribución, comprometida con la promoción de la justicia junto con el servicio de la Fe desde su mismo núcleo fundacional, no es admisible imponer a nadie una concepción de la justicia, como tampoco es posible renunciar a una visión de la interpretación del Derecho que busque la coherencia con la fidelidad al mensaje evangélico. Todo ello pertenece al campo de los motivos elevados y nobles, ${ }^{54}$ que constituyen un componente inseparable de una civilización superior y que no pueden estar ausente del mensaje educativo, que es, al decir de Rodó, un género de oratoria sagrada que se dirige a la juventud; idea casi idéntica a la que contiene la constitución apostólica Ex Corde Ecclesiae sobre las universidades católicas, cuando afirma que es su objetivo llevar adelante una ardiente búsqueda

\footnotetext{
51 Gustavo Zagrebelsky- Carlo María Martini, La exigencia de justicia (Madrid: Trotta, 2006).

52 Filippo Vassalli, "La missione del giurista nell'elaborazione delle leggi", in Studi giuridici (Milano, Giuffrè, 1960), pp. 737-751.

53 Paolo Grossi, Ritorno al diritto (Bari: Laterza, 2015).

${ }_{54}$ Paolo Grossi, Nobilta del diritto. Profili di giuristi (Milano: Giuffre, 2008), coll. Per la storia del pensiero giuridico moderno, No. 80 .
} 
de la verdad y su transmisión desinteresada a los jóvenes y a todos aquellos que aprenden a razonar con rigor, para obrar con rectitud y para servir mejor a la sociedad.

La formación de ese criterio elevado y noble, sustentado en la disciplina y en la virtud personal, no es separable de la adquisición de la idoneidad para agregar a la ley, aquello que le falta para convertirse en Derecho. En su Discours préliminaire, Portalis, consciente de que la ley no puede preverlo todo, encontraba el adecuado suplemento en el depósito de máximas, decisiones y doctrina, cuyo conocimiento es imprescindible a quienes aplicarán el Derecho, por medio de un hábito de ciencia y de razón que suaviza y ordena el poder. No es sino el hábito de ciencia y de razón logrado por medio del estudio, lo que humaniza la ley hasta lograr el Derecho.

La aplicación del Derecho resultará, pues, necesariamente, de la tensión entre la respuesta a esa vocación por la justicia, y el despojo de toda prepotencia y de todo despotismo, 55 que es la función que corresponde cumplir a la legislación abstracta y general.

Para citación: De Cores, Carlos, La interpretación del derecho como vocación, en Revista de Derecho N 19 (jul.-2019), ISSN 1510-3714, ISSN On line 2393-6193, $157-180$

\section{Contribución 100\% Carlos De Cores.}

\section{BIBLIOGRAFÍA}

Alpa, Guido, "Disertación al recibir la investidura de Doctor Honoris Causa de la Universidad de Buenos Aires en la Facultad de Derecho”, 27 de marzo de 2008.

Betti, Emilio, Teoría Generale dell'interpretazione, vol. I, Milano, Giuffré, 1955.

Calamandrei, Piero, "Fede nel diritto", Conferencia inédita presentada en Firenze el 21 de enero de 1940, citada por Guido Alpa en la disertación al recibir la investidura de Doctor Honoris Causa de la Universidad de Buenos Aires en la Facultad de Derecho, 27 de marzo de 2008.

55 Piero Calamandrei, "Fede nel diritto", Conferencia inédita presentada en Firenze el 21 de enero de 1940; el texto se encuentra en proceso de publicación con la Editorial Laterza. citado por Guido Alpa en "Las tareas del Derecho privado", discurso pronunciado en oportunidad de su doctorado honoris causa por la Universidad de Buenos Aires. 
Caumont, Arturo, "La función jurisdiccional del magistrado es aplicar el Derecho Objetivo. Infungibilidad del poder normativo", en Revista de Derecho de la Universidad Católica del Uruguay, $\mathrm{N}^{\circ}$ VI (2004): 187 y ss.

Caumont, Arturo, Doctrina General del contrato. Proposiciones teóricas de innovación. Montevideo: La Ley Uruguay, 2014.

Cicerón, Marco Tulio, Topica. Hay varias ediciones.

Festi, Fiorenzo, "L'arbitrato di equità", en Contratto e impresa, Padova: Cedam, 2006.

Gadamer, Hans-Georg, Verdad y método, Salamanca: Ediciones Sígueme, 2003.

Gamarra, Jorge, "Las circunstancias del caso concreto en la interpretación y aplicación de la ley “, en Revista de Doctrina y Jurisprudencia de Derecho Civil, FCU, tomo II (2014)

Granelli, Carlo, "La giurisprudenza è fonte di diritto?": Introduzione ad un incontro di studi, 30 settembre 2016, in occasione della presentazione dei due volumi degli "Scritti giuridici di Andrea Belvedere”, Padova, 2016, en www.iuscivile.it.

Grossi Paolo, "Modernità política e ordine giuridico", en Quaderni Fiorentini 27 (1998).

Grossi, Paolo, "Il disagio di un legislatore (Filippo Vassalli e le aporie del assolutismo giuridico)", en Quaderni Fiorentini XXVI (2007).

Grossi, Paolo, "Le molte vite del giacobinismo giuridico", en Mitologie giuridiche della modernitá, Milano: Giuffre, 2007.

Grossi, Paolo, "Nobiltà del diritto. Profili di giuristi", en Collana per la storia del pensiero giuridico moderno, No. 80 (2008), Milano: Giuffre.

Grossi, Paolo, Ritorno al diritto, Bari: Laterza, 2015.

Guastini, Riccardo, L'interpretazione dei documenti normativi, Milano: Giuffre, 2004.

Guzmán Brito, Alejandro, "Dialéctica y retórica en los “Topica” de Cicerón”, en Revista de Estudios histórico-jurídicos, XXXII (2010), Valparaíso, Chile, 161-195.

Irti, Natalino, "Moralita de l'analisi linguistico", en www.juscivile.it.

Montesquieu, Carlos Luis, El espiritu de las leyes. Madrid: Biblioteca de derecho y ciencias sociales, Librería General de Victoriano Suárez, 1906, tomo I.

Pellecchi, Luigi, "La costruzione retorica della sentenza”, Relazione tenuta dall'Autore presso la Scuola Superiore della Magistratura, nell'ambito del Corso Il linguaggio della giurisdizione, Firenze: Accademia della Crusca, 20 giugno 2016, en www.juscivile.it

Sarlo, Oscar, "Derechos fundamentales y proceso concursal”, en Anuario de Derecho Civil Uruguayo, tomo XXXIX, FCU, Montevideo (2009). 
Sarlo, Oscar, "El marco teórico en la investigación dogmática”, en Observar la ley: ensayos sobre metodología de la investigación jurídica, coord. por Christian Courtis; Manuel Atienza Rodríguez (pr.), Madrid: Trotta, 2006., p. 175-208.

Sciumè, Alberto, "I principi generali del diritto nell'ordine giuridico contemporaneo (18371942)", en Il diritto nella storia, Collana diretta da Umberto Santarelli, Torino: Giappichelli, 2002.

Tomás de Aquino, Summa Theologiae, I-II, q.90

Van Rompaey, Leslie, "Hacia una jurisprudencia principialista”, en Revista de Derecho de la Universidad Católica del Uruguay (2004).

Vassalli, Filippo, "Estrastatualitá del diritto civile", en Studi in onore di Antonio Cicu, Milano: Giuffre, 1951, Volumen segundo.

Vassalli, Filippo, "La missione del giurista nell'elaborazione delle leggi", en Studi giuridici, Milano: Giuffrè, 1960.

Zagrebelsky, Gustavo-Martini, Carlo María, La exigencia de justicia, Madrid: Trotta, 2006. 